\title{
Relação fósforo e magnésio na fertilidade do solo, no estado nutricional e na produção da alfafa $^{1}$
}

\author{
Adônis Moreira², Reges Heinrichs ${ }^{3}$, Alfredo Ribeiro de Freitas ${ }^{2}$ \\ 1 Projeto parcialmente financiado pela FAPESP. \\ 2 Embrapa Pecuária Sudeste, SP. Bolsista CNPq. \\ ${ }^{3}$ Unesp - Campus Experimental de Dracena, SP.
}

RESUMO - Com o objetivo de avaliar a influência da relação P:Mg na fertilidade do solo, no estado nutricional e na produção de matéria seca da alfafa, foi realizado um experimento em vasos com Latossolo Vermelho Amarelo distrófico, segundo delineamento inteiramente casualizado, em esquema de parcelas subdivididas, com três repetições. Os tratamentos foram constituídos de combinações de P (doses: 0, 100, 200 e $400 \mathrm{mg} \mathrm{kg}^{-1}$, fonte: superfosfato triplo) e Mg (doses: 0 , 100 e $200 \mathrm{mg} \mathrm{kg}^{-1}$, fonte: cloreto de magnésio), nas proporções de 0, 0,5, 1, 2 e 4. No período experimental, foram realizados três cortes, com intervalo de 30 dias (subparcelas). Os resultados demonstraram que o incremento da relação P:Mg e das doses de P e de Mg aumenta a produção de matéria seca. O teor de P e as combinações de P:Mg no tecido vegetal apresentaram estreita relação com a proporção desses nutrientes no solo. A relação 2:1 acarretou maior teor de clorofila e $\mathrm{N}$ na matéria seca, enquanto altas quantidades de P no solo diminuíram a absorção de K.

Palavras-chave: Medicago sativa, clorofila, composição mineral, macronutrientes

\section{Phosphorus and magnesium ratio on soil fertility, nutritional status, and yield of alfalfa}

\begin{abstract}
A greenhouse experiment was carried out to evaluate the effect of P:Mg ratios on soil fertility and on mineral composition and yield of alfalfa cultivated in a dystrophic Red Yellow Latosol (Oxisol). It was used a split-plot in a complete randomized design, with three replicates. Treatments were combinations of $\mathrm{P}$ (rates: 0,100 , 200, and $400 \mathrm{mg} \mathrm{kg}^{-1}$, source: triple superphosphate) and $\mathrm{Mg}$ (rates: 0,100 , and $200 \mathrm{mg} \mathrm{kg}^{-1}$, source: magnesium chlorite) at the following P:Mg ratios: 0 , 0.5, 1, 2, and 4. Three harvest were performed (subplots), with 30-d intervals. Results showed that dry matter yield increased with the increment of $\mathrm{P}: \mathrm{Mg}$ ratios and $\mathrm{P}$ and $\mathrm{Mg}$ rates. Phosphorus concentrations and $\mathrm{P}: \mathrm{Mg}$ ratios in tissue showed close relationship with the proportion of the nutrients in the soil. The 2:1 ratio caused higher chlorophyll and $\mathrm{N}$ concentrations in tissue, while elevating quantity of $\mathrm{P}$ in soil decreased $\mathrm{K}$ uptake.
\end{abstract}

Key Words: Medicago sativa, chlorophyll, mineral composition, macronutrients

\section{Introdução}

Na nutrição de plantas, as interações de nutrientes são comuns, podendo ocorrer tanto na solução do solo como nas plantas (Robson \& Pitman, 1983). Na cinética de absorção, a velocidade de dado elemento pode ser aumentada, diminuída, ou não ser influenciada pela presença de outro íon, havendo, nesses casos, ocorrência de antagonismos, inibição competitiva ou não e sinergismos (Malavolta et al., 1997).

Nesse sentido, existem alguns casos comuns, como a presença do $\mathrm{Ca}^{2+}$ na solução do solo, impedindo a absorção exagerada de $\mathrm{Cu}^{2+}$, cuja toxidez é evitada (Malavolta et al., 1997), a presença de grande quantidade de $\mathrm{K}^{+}$induzindo a deficiência de $\mathrm{Mg}^{2+}$ (Marschner, 1995), a adubação fosfatada provocando a carência de $\mathrm{Zn}^{2+}$ (Malavolta et al., 1997; Havlin et al., 1999) e a dependência da absorção de nitrato em função da quantidade de P na solução do solo (Rufty et al., 1989), entre outros.

Segundo Malavolta et al. (1997), a absorção do P é influenciada pela concentração de Mg no meio, podendo o Mg ser carregador do P para dentro da planta. Acredita-se também que a existência da inter-relação desses dois íons é conseqüência da necessidade de $\mathrm{Mg}$ nas reações de transferência de energia (Bergmann, 1992). De qualquer modo, apesar de existirem resultados que indicam essa 
interação (Zhong et al., 1993; Mengel \& Kirkby, 2001), ainda não existem evidências diretas do efeito do P e Mg sobre a concentração de $\mathrm{Mg}$ ou P na solução do solo, no transporte para superfície das raízes e na absorção ou na translocação desses íons dentro das plantas (Skinner \& Matthews, 1990).

O objetivo neste trabalho foi avaliar, em casa de vegetação, as prováveis interações e a influência da relação P:Mg na fertilidade do solo, no estado nutricional e na produção de matéria seca (MS) da alfafa cultivada em Latossolo Vermelho Amarelo distrófico.

\section{Material e Métodos}

O experimento foi realizado em casa de vegetação do Centro de Energia Nuclear na Agricultura, da Universidade de São Paulo, localizado no Município de Piracicaba, SP, sob as coordenadas geográficas de $22^{\circ} 42^{\prime} 30^{\prime \prime}$ LS e 47038'00" LW.

Empregou-se o delineamento experimental inteiramente casualizado em esquema de parcelas subdivididas, com três repetições. Os tratamentos foram combinações de P (doses: 0, 100, 200, $400 \mathrm{mg} \mathrm{kg}^{-1}$, fonte: superfosfato triplo) e de $\mathrm{Mg}$ (doses: 0, 100 e $200 \mathrm{mg} \mathrm{kg}^{-1}$, fonte: cloreto de magnésio), nas proporções de $0,0,5,1,2$ e 4 . No período, foram realizados três cortes, com intervalo de 30 dias (subparcelas).

Utilizou-se um Latossolo Vermelho Amarelo distrófico, de textura média, coletado no Instituto de Zootecnia da Secretaria de Agricultura e Abastecimento de São Paulo, no Município de Nova Odessa, na profundidade de $0-20 \mathrm{~cm}$, com as seguintes características: $\mathrm{pH}\left(\mathrm{CaCl}_{2} 0,1 \mathrm{~mol} \mathrm{~L}^{-1}\right)=$ 4,3, matéria orgânica $=20,3 \mathrm{~g} \mathrm{~kg}^{-1}, \mathrm{P}($ Mehlich 1$)=6,0 \mathrm{mg} \mathrm{dm}^{-3}$, $\mathrm{P}($ resina $)=4,0 \mathrm{mg} \mathrm{dm}^{-3}, \mathrm{~K}$ (resina) $=1,0 \mathrm{mmol}_{\mathrm{C}} \mathrm{dm}^{-3}, \mathrm{Ca}$ (resina) $=3,0 \mathrm{mmol}_{\mathrm{C}} \mathrm{dm}^{-3}, \mathrm{Mg}($ resina $)=2,0 \mathrm{mmol}_{\mathrm{C}} \mathrm{dm}^{-3}, \mathrm{Al}(\mathrm{KCl}$ $\left.1,0 \mathrm{molL}^{-1}\right)=21 \mathrm{mmol}_{\mathrm{C}} \mathrm{dm}^{-3}, \mathrm{H}+\mathrm{Al}=96 \mathrm{mmol}_{\mathrm{C}} \mathrm{dm}^{-3}, \mathrm{~V}=6,0 \%$, $\mathrm{B}$ (água quente) $=0,5 \mathrm{mg} \mathrm{kg}^{-1}$, Cu (Mehlich 1) $=1,2 \mathrm{mg} \mathrm{dm}^{-3}$, Fe $($ Mehlich 1$)=45,0 \mathrm{mg} \mathrm{dm}^{-3}, \mathrm{Mn}$ (Mehlich 1$)=11,1 \mathrm{mg} \mathrm{dm}^{-3}$ e Zn (Mehlich 1) = 1,5 $\mathrm{mg} \mathrm{dm}^{-3}$.

Em vasos de barro, impermeabilizados internamente, foram colocados $3,0 \mathrm{dm}^{3}$ de solo seco ao ar (TFSA), passado em peneira de 2,0 mm. A acidez foi corrigida com $\mathrm{CaCO}_{3}$ (p.a.), para elevar a saturação por bases a 80\% (Werner et al., 1996). Exceto o N, o P e o Mg, a adubação com K, B, Cu, Mn e Zn foi feita de acordo com Malavolta (1980), para experimentos conduzidos em casa de vegetação $\left(50 \mathrm{mg} \mathrm{kg}{ }^{-1}\right.$ de $\mathrm{K}$, na forma de $\mathrm{KCl} ; 0,5 \mathrm{mg} \mathrm{kg}^{-1} \mathrm{de} \mathrm{B}$, na forma de $\mathrm{H}_{3} \mathrm{BO}_{3}$; $1,5 \mathrm{mg} \mathrm{kg}^{-1} \mathrm{de} \mathrm{Cu}$, na forma de $\mathrm{CuSO}_{4} ; 5,0 \mathrm{mg} \mathrm{kg}^{-1} \mathrm{de} \mathrm{Mn}$, na forma de $\mathrm{MnSO}_{4}$; e 5,0 mg kg-1 de $\mathrm{Zn}$, na forma de
$\mathrm{ZnSO}_{4}$ ). O solo nos vasos foi irrigado diariamente com água desionizada, para compensar as perdas por evapotranspiração e manter o solo próximo de $70 \%$ do valor total de poros (VTP).

As sementes da alfafa (cultivar Florida 77), após a escarificação, foram inoculadas com Sinorhizobium meliloti e, posteriormente, tratadas com $0,01 \mathrm{mg} \mathrm{L}^{-1}$ de Co e $0,1 \mathrm{mg} \mathrm{L}^{-1}$ de Mo. Nos vasos, foram semeadas dez sementes e, após o desbaste, foram deixadas três plantas uniformes. Três meses após a semeadura, foi realizada, na altura de $10 \mathrm{~cm}$ da superfície do solo, a primeira colheita de um total de três com intervalo de 30 dias. Após cada corte, a forragem colhida foi seca a $\pm 65^{\circ} \mathrm{C}$, pesada para obtenção da MS e posteriormente moída para determinação dos teores totais de $\mathrm{N}, \mathrm{P}, \mathrm{K}, \mathrm{Ca}, \mathrm{Mg}$ e $\mathrm{S}$ na parte aérea (Malavolta et al., 1997). Antes de cada corte, foi realizada a leitura SPAD no terço médio e convertida em teor de clorofila $\left(\mu \mathrm{g} \mathrm{cm}^{-2}\right)$ pela equação $\mathrm{Y}=-77,233+(3,54725 * \mathrm{SPAD})$ (Guimarães et al., 1999).

Foram coletadas amostras de solo em cada vaso com os respectivos tratamentos antes da semeadura e por ocasião das colheitas da parte aérea das plantas, para determinação de $\mathrm{pH}$ em água, $\mathrm{P}, \mathrm{K}, \mathrm{Ca}, \mathrm{Mg}, \mathrm{S}, \mathrm{Al}, \mathrm{H}+\mathrm{Al}$, CTC e saturação por bases (V\%), conforme metodologias descritas pela Embrapa (1997).

Os dados foram submetidos à analise de variância (teste F) e ao teste de comparação de contraste entre médias pelo teste Tukey, a 5\% de probabilidade (Pimentel Gomes \& Garcia, 2002). As análises de regressão foram usadas com o objetivo de verificar os efeitos das relações dos teores foliares totais de P e de Mg sobre a produção e o estado nutricional das plantas.

\section{Resultados e Discussão}

As relações P:Mg no solo mantiveram, nas três colheitas, as proporções próximas das estabelecidas no início do experimento (Tabela 1). Observou-se também que a aplicação de $\mathrm{CaCO}_{3}$ como corretivo da acidez foi eficiente na elevação da saturação por bases para valores próximos aos 80\% indicados por Werner et al. (1996), demonstrando que a incubação do solo por um mês e a manutenção da saturação de água no solo próxima a 70\% do VTP foi suficiente para proporcionar o equilíbrio completo das reações químicas do carbonato de cálcio, independentemente do poder de tampão do solo.

O pH e o teor de K trocável diminuíram com a sucessão de cortes, havendo neste caso redução nos valores após o terceiro corte de 10 e 50\%, em relação aos obtidos antes da 
semeadura, respectivamente (Tabela 1). Apesar da interação negativa $\mathrm{P} \times \mathrm{S}$ verificada por Moreira et al. (1997) na alfafa, o teor de $\mathrm{S}$ na planta não foi afetado pelo incremento da concentração de P no solo, havendo neste caso grande variação nos teores dentro dos tratamentos e nas épocas de coleta de solo (Tabela 1).

A exportação de cátions básicos (Ca e Mg) acarreta diminuição do pH (Jackson \& Reisenauer, 1984), o que é agravado com a atividade das raízes, aumentando o teor de ácido carbônico no solo (Smucker, 1984). De acordo com Mills et al. (1989), a atividade dos microrganismos, em particular os que atuam em desnitrificação, desaminação, nitrificação quimiotrófica, redução do sulfato e oxidação do $\mathrm{S}^{2-}$, entre outros, também aumentam a acidez do solo.No caso do K, o nutriente mais requerido pela alfafa (Rassini \& Freitas, 1998), a diminuição da sua quantidade no solo está diretamente relacionada à exportação resultante da produção de MS. Para cada 10 toneladas de MS, a alfafa bem nutrida necessita, em média, de $500 \mathrm{~kg} \mathrm{ha}^{-1}$ de K (Rhykerd \& Overdahl, 1972). O mesmo foi observado por Moreira et al. (2005), que, estudando a relação Ca:Mg na fertilidade do Latossolo Vermelho Escuro, também verificaram que, após cortes sucessivos, o $\mathrm{K}$ foi o nutriente mais exportado. Independentemente da época de corte, o aumento da relação

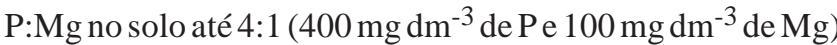
proporcionou incremento linear significativo sobre a produção de MS da alfafa (Figura 1a). Os resultados não demonstraram relação positiva do $\mathrm{Mg}$ na atividade enzimática das quinases para aumentar a absorção de $\mathrm{P}$ (Adams, 1980) e de praticamente todas as enzimas fosforilativas dependerem da presença do $\mathrm{Mg}$, na formação da ponte entre o ATP ou o ADP com a molécula da enzima (Malavolta et al., 1997), e serem responsáveis pela fotossíntese, pela síntese de compostos orgânicos e pelo aumento do volume de raízes, com conseqüente aumento da produção de forragem.

À semelhança do ocorrido com a relação P:Mg, a produção de MS apresentou correlação positiva com o teor foliar de P (Figura 1b), em que, exceto na testemunha, os teores de $\mathrm{P}$ ficaram acima de $4,0 \mathrm{~g} \mathrm{~kg}^{-1}$, valor superior ao nível de suficiência de $3,0 \mathrm{~g} \mathrm{~kg}^{-1}$, descrito por Rhykerd \& Overdahl (1972) para cultura da alfafa. Com relação ao efeito do teor foliar de Mg sobre a produção de MS, verificou-se que a adubação com este nutriente resultou em resposta

Tabela 1 - Análise química do solo antes da semeadura e após os três cortes da alfafa

\begin{tabular}{|c|c|c|c|c|c|c|c|c|c|}
\hline P:Mg & $\mathrm{pH}$ & $\mathrm{P}$ & $\mathrm{S}-\mathrm{SO}_{4}$ & $\mathrm{~K}$ & $\mathrm{Ca}$ & Mg & CTC & V & $\mathrm{P}: \mathrm{Mg}^{(1)}$ \\
\hline
\end{tabular}

\begin{tabular}{|c|c|c|c|c|c|c|c|c|c|}
\hline 0 & 6,6 & 2 & - & 3,2 & 26 & 4 & 44,2 & 75,1 & 0,04 \\
\hline 0,5 & 6,4 & 44 & - & 1,6 & 22 & 14 & 47,6 & 78,9 & 0,26 \\
\hline 1 & 6,3 & 44 & - & 2,0 & 19 & 13 & 45,0 & 75,6 & 0,28 \\
\hline 2 & 6,2 & 64 & - & 2,2 & 24 & 9 & 46,2 & 76,2 & 0,59 \\
\hline 4 & 6,2 & 112 & - & 2,1 & 26 & 13 & 53,1 & 77,4 & 0,72 \\
\hline & \multicolumn{9}{|c|}{ Após o $1 \underline{0}$ corte } \\
\hline 0 & 6,1 & 2 & 6,0 & 3,6 & 27 & 4 & 45,6 & 75,9 & 0,04 \\
\hline 0,5 & 6,2 & 42 & 6,2 & 2,8 & 27 & 17 & 56,8 & 82,4 & 0,21 \\
\hline 1 & 6,6 & 50 & 4,8 & 2,9 & 24 & 12 & 48,9 & 79,6 & 0,35 \\
\hline 2 & 6,4 & 68 & 8,5 & 2,8 & 24 & 10 & 46,8 & 78,6 & 0,67 \\
\hline 4 & 5,7 & 96 & 9,7 & 1,8 & 25 & 5 & 44,8 & 71,0 & 1,60 \\
\hline
\end{tabular}

\begin{tabular}{|c|c|c|c|c|c|c|c|c|}
\hline 0 & 5,6 & 2 & 3,5 & 0,9 & 30 & 8 & 51,9 & 74,9 \\
\hline 0,5 & 6,0 & 41 & 8,5 & 1,0 & 21 & 21 & 55,0 & 78,2 \\
\hline 1 & 5,8 & 52 & 3,5 & 1,6 & 21 & 19 & 52,6 & 79,1 \\
\hline 2 & 5,7 & 78 & 11,0 & 1,4 & 19 & 12 & 44,4 & 72,9 \\
\hline 4 & 6,1 & 128 & 11,0 & 2,0 & 25 & 13 & 51,0 & 78,5 \\
\hline
\end{tabular}

Após o $3 \underline{0}$ corte

\begin{tabular}{|c|c|c|c|c|c|c|c|c|c|}
\hline 0 & 5,8 & 2 & 4,7 & 1,8 & 30 & 4 & 50,8 & 70,5 & 0,04 \\
\hline 0,5 & 5,6 & 80 & 3,5 & 0,8 & 25 & 13 & 55,8 & 69,6 & 0,51 \\
\hline 1 & 5,6 & 96 & 8,2 & 0,9 & 26 & 13 & 54,9 & 72,7 & 0,62 \\
\hline 2 & 5,8 & 100 & 7,2 & 0,9 & 26 & 13 & 54,9 & 72,7 & 0,64 \\
\hline 4 & 5,8 & 128 & 6,0 & 1,1 & 25 & 6 & 45,1 & 71,2 & 1,78 \\
\hline
\end{tabular}

${ }^{1}$ Relação entre o P e Mg disponível do solo. ${ }^{\mathrm{P}}$ disponível e $\mathrm{K}$ trocável - extrator Mehlich 1 ; Ca, Mg e $\mathrm{Al}$ trocáveis - extrator $\mathrm{KCl} 1$ mol L-1; $\mathrm{H}+\mathrm{Al}$ - tampão $\mathrm{SMP} ; \mathrm{S}-\mathrm{SO}_{4}$ - extrator $0,1 \mathrm{~mol} \mathrm{~L}-1 \mathrm{Ca}\left(\mathrm{H}_{2} \mathrm{PO}_{4}\right)_{2} \cdot \mathrm{H}_{2} \mathrm{O}$. 
quadrática e positiva, com cerca de $65 \%$ dos teores situados entre 2,5 e 3,6 $\mathrm{g} \mathrm{kg}^{-1}$ de Mg (Figura 1c), valores próximos do nível crítico de 3,0 $\mathrm{g} \mathrm{kg}^{-1}$, também proposto por Rhykerd \& Overdahl (1972), porém abaixo de 4,4 $\mathrm{g} \mathrm{kg}^{-1}$, encontrado por Moreira et al. (1999), no estudo da relação Ca:Mg em alfafa cultivada em casa de vegetação em Latossolo Vermelho Escuro distrófico, fase cerrado.

a

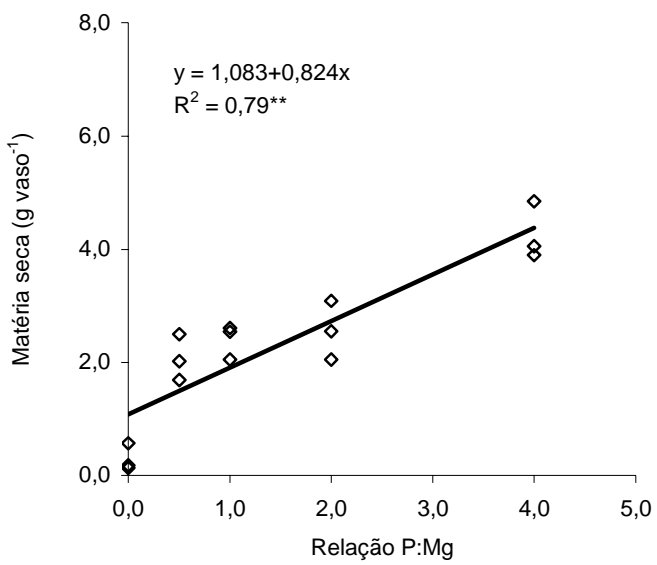

b

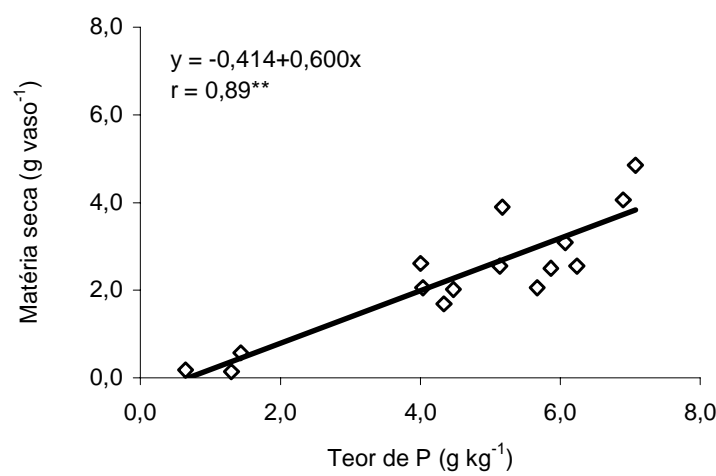

C

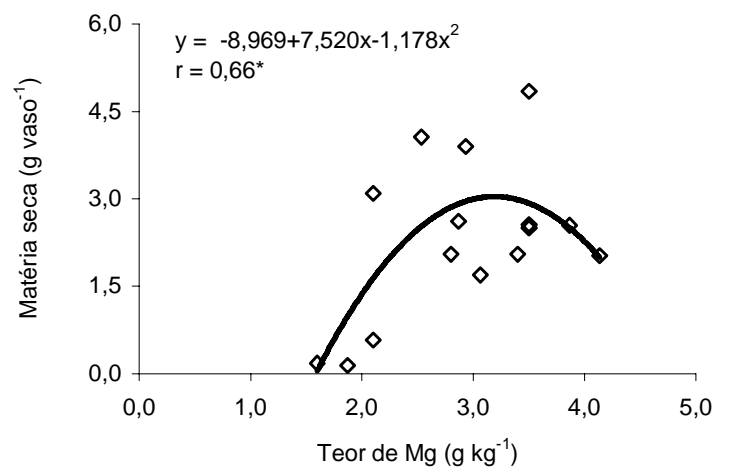

Figura 1 - Produção de matéria seca da alfafa em função da relação P:Mg na adubação (a) e dos teores foliares de $\mathrm{P}$ (b) e $\mathrm{Mg}$ (c) na matéria seca da alfafa em três cortes. * $\mathrm{e}^{* *}$ significativo, respectivamente, a 5 e $1 \%$ de probabilidade pelo teste $\mathrm{F}$.
O teor de P na MS da parte área foi significativamente influenciado pela relação $\mathrm{P}: \mathrm{Mg}$ no solo, o mesmo não ocorrendo com o teor foliar de Mg (Figuras 2a e 2b). Observou-se também que o incremento obtido no teor foliar de $\mathrm{P}$, à semelhança do teor de $\mathrm{Mg}$, está diretamente relacionado às quantidades utilizadas para obtenção das concentrações de $\mathrm{P}$ e de $\mathrm{Mg}$ disponíveis no solo, não

a

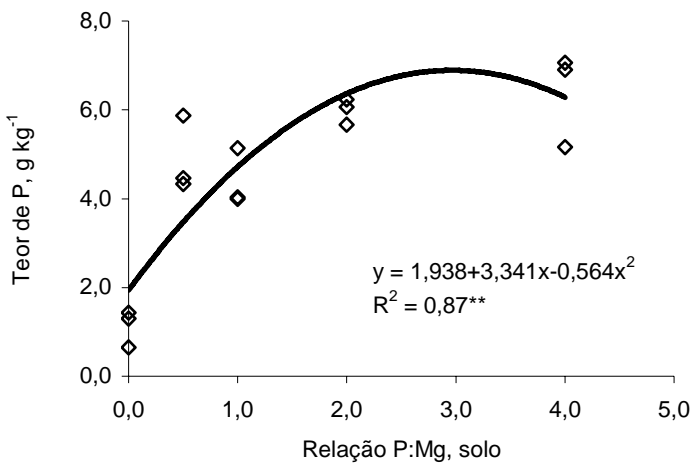

b

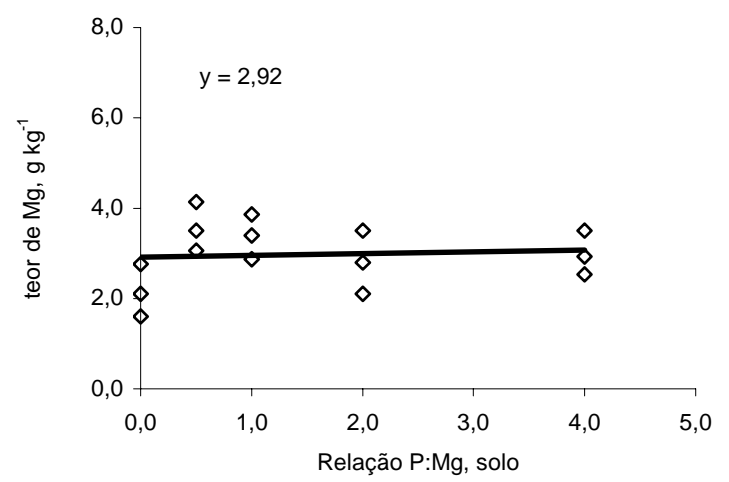

C

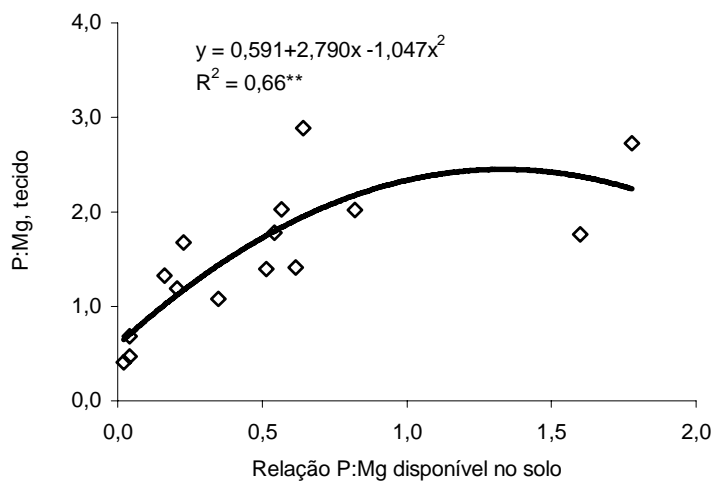

Figura 2 - Efeito da relação P:Mg do solo com os teores de P (a) e Mg (b) na matéria seca da alfafa em três cortes e da relação P:Mg disponível no solo com a relação do teor foliar de $\mathrm{P}: \mathrm{Mg}$ (c). ** significativo a $1 \%$ de probabilidade pelo teste $F$. 
Tabela 2 - Teor de clorofila e concentração de N, K, Ca e S na matéria seca da parte aérea da alfafa

\begin{tabular}{|c|c|c|c|c|c|c|c|}
\hline $\mathrm{P}$ & $\mathrm{Mg}$ & Relação & Clorofila & $\mathrm{N}$ & $\mathrm{K}$ & $\mathrm{Ca}$ & $\mathrm{S}$ \\
\hline & & $\mathrm{P} / \mathrm{Mg}$ & $\mathrm{mg} \mathrm{cm}^{-2}$ & & _ & & - \\
\hline 0 & 0 & 0 & 221,3 & 32,4 & 20,7 & 27,9 & 2,1 \\
\hline 100 & 200 & 0,5 & 261,4 & 33,0 & 18,0 & 21,6 & 2,2 \\
\hline 100 & 100 & 1 & 280,9 & 32,4 & 18,5 & 24,2 & 2,1 \\
\hline 200 & 100 & 2 & 283,4 & 34,3 & 18,7 & 21,1 & 2,3 \\
\hline 400 & 100 & 4 & 209,2 & 33,1 & 17,0 & 24,2 & 2,1 \\
\hline Média & & & 251,2 & 33,0 & 18,6 & 23,8 & 2,2 \\
\hline Efeito liı & & & ns & ns & $*$ & ns & ns \\
\hline Efeito qu & & & $* *$ & $*$ & ns & ns & ns \\
\hline
\end{tabular}

${ }^{*}$ e ${ }^{* *}$ significativo a 5 e $1 \%$ pelo teste $F$, respectivamente; ${ }^{n s}$ não-significativo. Média de três épocas de cortes e de três repetições.

havendo neste caso interação dos nutrientes na absorção, o que difere dos resultados relatados na literatura, por Skinner \& Matthews (1990), em parreira, e por Zhong et al. (1993), em mudas mamoneira, de que a disponibilidade do P é um fator decisivo para a mobilização, absorção e a translocação do Mg para dentro da planta. A provável causa desse efeito talvez seja a baixa exigência de Mg pela alfafa (Moreira et al., 2007), sendo a aplicação de $100 \mathrm{mg} \mathrm{dm}^{-3}$ suficiente para suprir toda exigência nutricional, mesmo com baixas concentrações de P no solo.

Da mesma forma do P, as relações entre os íons estudados influenciaram de forma quadrática e significativa as relações de P:Mg na MS da parte aérea (Figura 2c). Verificou-se também que os teores de $\mathrm{P}$ na MS estão diretamente relacionados à concentração do nutriente no solo. O mesmo foi observado com o Mg. Estes resultados corroboram os obtidos por Moreira \& Malavolta (2001), com P, e por Moreira et al. (1999), com Mg (Figura 3).

Os teores foliares de N, K e clorofila foram significativamente influenciados pela aplicação de fósforo e magnésio, havendo, no caso da clorofila e do $\mathrm{N}$, respostas positivas e quadráticas (Tabela 2), com ponto de máxima produção próximo à relação 2:1. O P atua no armazenamento e na transferência da energia utilizada na fixação simbiótica no $\mathrm{N}$ e no transporte eletrônico na fotossíntese, enquanto o Mg, além de fazer parte da estrutura da molécula da clorofila, é também co-fator da hidrólise do ATP, fornecendo energia para fixação do $\mathrm{N}_{2}$ atmosférico (Marschner, 1995; Malavolta et al., 1997).

Pela análise de regressão observou-se efeito linear significativo e negativo das concentrações de P e Mg sobre o teor de K, observando-se diminuição de $18 \%$ dos teores da testemunha para a relação 4:1 (Tabela 2). Este resultado demonstra que, além do efeito de diluição descrito por Malavolta et al. (1997), existiu o efeito de inibição entre o Mg e o K (Marschner, 1995), verificado na relação 1:1. Comportamento semelhante também foi relatado por Stivers \& Ohlrogge (1952) e Andrew \& Robins (1969), que verificaram
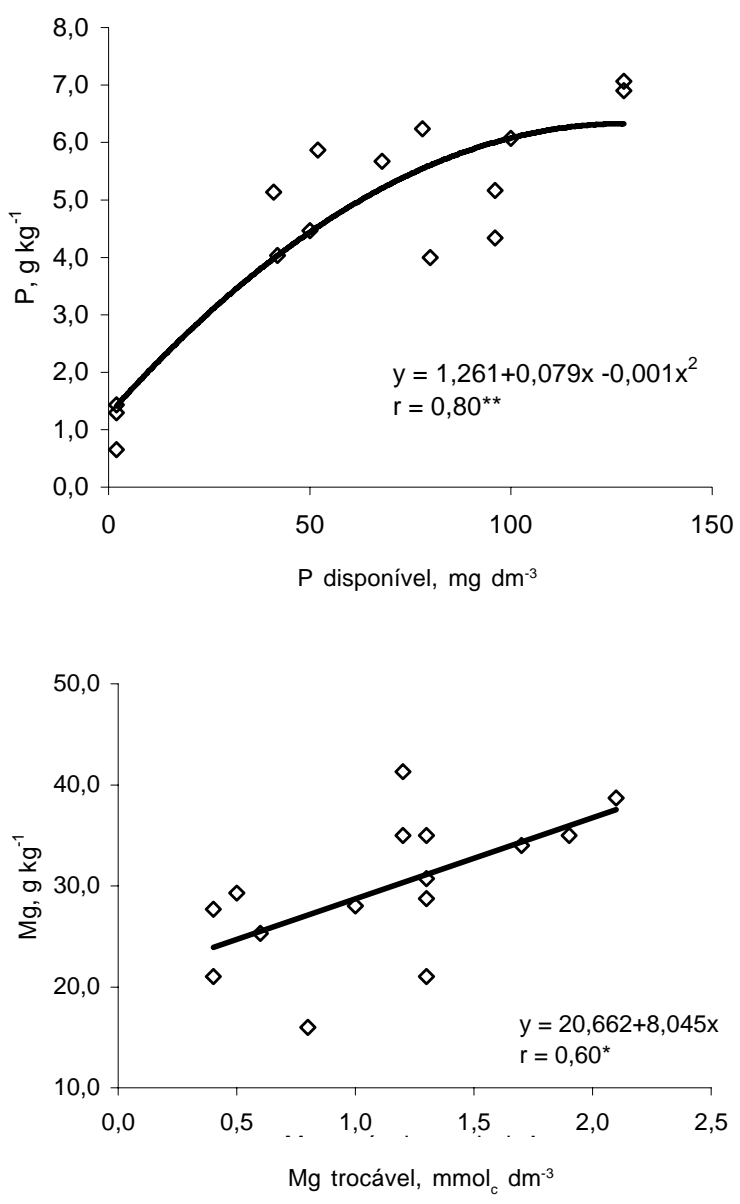

Figura 3 - Relação entre a quantidade de P disponível e magnésio trocável no solo com suas concentrações na matéria seca da parte aérea da alfafa em três cortes. * e ** significativo, respectivamente, a 5 e $1 \%$ pelo teste $\mathrm{F}$.

diminuição do teor foliar de K em leguminosas, em razão do aumento da concentração de P no solo. Apesar da variação dos teores de $\mathrm{K}$, na média, esses teores mantiveram-se acima do nível crítico de 13,3 a 13,6 g kg-1 $^{-1}$ de K estabelecido com a cultivar Crioula, por Rando \& Silveira (1995).

A variação da relação P:Mg não se refletiu nos teores de Ca e S na MS da parte aérea (Tabela 2). Mesmo o cálcio fazendo parte da composição do superfosfato triplo, a 
correção da acidez do solo para alcançar saturação por bases de $80 \%$ com $\mathrm{CaCO}_{3}$ foi suficiente para não ocasionar variação significativa no teor de Ca, que permaneceu na faixa de suficiência de 8 a $30 \mathrm{~g} \mathrm{~kg}^{-1}$ descrita por Rhykerd \& Overdahl (1972). O teor de S na MS ficou, em média, acima do nível crítico de 1,5 $\mathrm{g} \mathrm{kg}^{-1}$ obtido com a cultivar Crioula em Latossolo Vermelho Escuro, fase cerrado, por Moreira et al. (1997).

\section{Conclusões}

A relação P:Mg do solo e os teores de $\mathrm{P}$ e $\mathrm{Mg}$ no tecido vegetal tiveram influência significativa sobre a produção de matéria seca da alfafa.

A relação 2:1 acarretou o maior teor de clorofila e nitrogênio, enquanto altas quantidades de P no solo diminuíram a absorção de K.

As relações P:Mg não afetaram o teor foliar Ca e S presente na matéria seca.

\section{Literatura Citada}

ADAMS, F. Interactions of phosphorus with other elements in soils and in plants. In: KHASAWNWEH, F.E.; SAMPLE, E.C.; KAMPRATH, E.J. (Eds.). The role of phosphorus in agriculture. Madison: American Society of Agronomy, 1980. p.655-680.

ANDREW, C.S.; ROBINS, M.F. The effect of phosphorus on the growth and chemical composition of some tropical pasture legumes. Australian Journal Agricultural Research, v.20, p.675-685, 1969.

BERGMANN, W. Nutrition disorders of plants; development, visual, and analytical diagnosis. New York: Gustave Fischer Verlag, 1992. 741p.

EMPRESA BRASILEIRA DE PESQUISA E AGROPECUÁRIA EMBRAPA. Manual de métodos de análise de solo. Rio de Janeiro: EMBRAPA-CNPS, 1997. 212p.

GUIMARÃES, T.G.; FONTES, P.C.R.; PEREIRA, P.R.G.; et al. Teores de clorofila determinados por medidor portátil e sua relação com formas de nitrogênio em folhas de tomateiro cultivados em dois tipos de solo. Bragantia, v.58, n.1, p.209216, 1999.

HAVLIN, J.; BEATON, J.D.; TISDALE, S.L. et al. Soil fertility and fertilizers: an introduction nutrient management. Upper Saddle River: Prentice Hall, 1999. 499p.

JACKSON, T.L.; REISENAUER, H.M. Crop response to lime in the Western United States. In: ADAMS, F.; DINAUER, R.; GATES, K.E. et al. (Eds.). Soil acidity and liming. Madison: American Society of Agronomy, 1984. p.333-347.

MALAVOLTA, E. Elementos de nutrição mineral de plantas. Piracicaba: Agronômica Ceres, 1980. 251p.

MALAVOLTA, E.; VITTI, G.C.; OLIVEIRA, S.A. Avaliação do estado nutricional das plantas: princípios e aplicações. Piracicaba: Potafós, 1997. 319p.

MARSCHNER, H. Mineral nutrition of higher plants. London: Academic Press, 1995. 889p.
MENGEL, L.; KIRKBY, E.A. Principles of plants nutrition. Bern: International Potash Institute, 2001. 849p.

MILLS, A.L.; BELL, D.E.; HERLIKY, A.R. Microbes, sediments and acidified water: the importance of biological buffering. In: RAO, S.S. (Ed.). Acid stress and aquatic microbial interactions. Boca Raton: CRC Press, 1989. p.1-20.

MOREIRA, A.; BERNARDI, A.C.C.; RASSINI, J.B. et al. Fertilidade do solo e estado nutricional da alfafa cultivada nos trópicos. São Carlos: Embrapa Pecuária Sudeste, 2007. 40p.

MOREIRA, A.; CARVALHO, J.G.; EVANGELISTA, A.R. Efeito de doses de enxofre na produção e composição mineral da alfafa. Pesquisa Agropecuária Brasileira, v.32, p.533-538, 1997.

MOREIRA, A.; CARVALHO, J.G.; EVANGELISTA, A.R. Influência da relação cálcio e magnésio do corretivo na nodulação, produção e composição mineral da alfafa. Pesquisa Agropecuária Brasileira, v.34, p.249-255, 1999.

MOREIRA, A.; CARVALHO, J.G.; EVANGELISTA, A.R. Relação cálcio e magnésio na fertilidade de um Latossolo Vermelho Escuro distrófico cultivado com alfafa. Ciência e Agrotecnologia, v.29, p.786-794, 2005.

MOREIRA, A.; MALAVOLTA, E. Fontes, doses e extratores de fósforo em alfafa e centrosema. Pesquisa Agropecuária Brasileira, v.36, p.1519-1527, 2001.

PIMENTEL GOMES, F.; GARCIA, C.H. Estatística aplicada a experimentos agronômicos e florestais. Piracicaba: Fundação de Estudos Agrários Luiz de Queiroz, 2002. 309p.

RANDO, E.M.; SILVEIRA, R.I. Desenvolvimento da alfafa em diferentes níveis de acidez, potássio e enxofre no solo. Revista Brasileira de Ciência do Solo, v.19, p.235-242, 1995.

RASSINI, J.B.; FREITAS, A.R. Desenvolvimento da alfafa (Medicago sativa L.) sob diferentes doses de adubação potássica. Revista Brasileira de Zootecnia, v.27, p.487-490, 1998.

RHYKERD, C.L.; OVERDAHL, C.J. Nutrition and fertilizer use. In: HANSON, C.H. (Ed.). Alfalfa science and technology. Madison: American Society of Agronomy, 1972. v.2, p.437-465.

ROBSON, A.D.; PITMAN, M.G. Interactions between nutrients in higher plants. In: LAUCHLI, A.; BIELESKI, R.L. (Eds.). Encyclopedia of plant physiology. Berlin: Springer-Verlag, 1983. p.147-180.

RUFTY, T.W.; MACKOWN, C.T.; ISRAEL, D.W. Altered nitrate assimilation in P-stressed plants. Plant Physiology, v.89, p.16 (supplement), 1989.

SKINNER, P.W.; MATTHEWS, M.A. A novel interaction of magnesium translocation with the supply of phosphorus to roots of grapevine (Vitis vinifera L.). Plant, Cell and Environment, v.13, p.821-826, 1990.

SMUCKER, A.J.M. Carbon utilization and losses by plant root systems. In: BARBER, S.A.; BOUDIN, D.R.; KRAL, D.M. et al. (Eds.). Roots, nutrients and water influx, and plant growth. Madison: American Society of Agronomy, 1984. p.27-46.

STIVERS, R.K.; OHLROGGE, A.J. Influence of phosphorus and potassium fertilization of two soil types on alfalfa yield, stand, and content of these elements. Agronomy Journal, v.44, p.618-621, 1952.

WERNER, J.C.; PAULINO, V.T.; CANTARELLA, H. et al. Forrageiras. In: Van RAIJ, B.; CANTARELLA, H.; QUAGGIO, J.A. et al. (Eds.). Recomendação de adubação e calagem para o Estado de São Paulo. Campinas Instituto Agronômico de Campinas, 1996. p.245-258. (Boletim, 100).

ZHONG, W.; SCHOBERT, C.; KOMOR, E. Transport of magnesium ions in the phloem of Ricinus communis L. seedlings. Planta, v.190, p.114-119, 1993. 